\title{
Antioxidant and Anti-Tyrosinase Activity from Olea Leaf Extract Depended on Seasonal Variations and Chromagraphy Treatment
}

\author{
Dao-Mao Yang ${ }^{1}$, Ming-An Ouyang ${ }^{2 *}$ \\ ${ }^{1}$ Department of Biotechnology and Bioengineering, Huaqiao University, Xiamen, China \\ ${ }^{2}$ Key Laboratory of Biopesticide and Chemistry Biology, Ministry of Education, \\ Fujian Agriculture and Forestry University, Fuzhou, China \\ Email: *maouyang@hqu.edu.cn
}

Received October 20, 2012; revised November 27, 2012; accepted December 8, 2012

\begin{abstract}
In the present study, olive leaf extract, harvested from four seasons, extracted with solvent (methanol and water), was treated by D101 and Sephadex LH-20, and divided into 10 fractions by TLC detection. The antioxidant activity was evaluated using DPPH, superoxide anion scavenging and reducing power assays. Tyrosinase inhibitory activity was also performed with L-DOPA as substrate. On extraction method, there is no significant difference in methanol and water. Among 12 months, autumn showed the best harvest time in whole. OLE showed $90 \%$ tyrosinase inhibitory activity and inhibition type was non-competitive competition. By chromagraphy treatment, the ingredients of polysacchmaride and protein showed high bioactivity towards antioxidant and anti-tyrosinase activity, the rest part showed different extent of activity and prove some effect by chromatography treatment indirectly. OLE might be a valuable bioactive source and can be applicable in both the cosmetic and medical use.
\end{abstract}

Keywords: Olive Leaf Extract; Antioxidant Activity; Tyrosinase Inhibitory Activity; Non-Competitive Competition; Chromagraphy Treatment

\section{Introduction}

In recent years, focus on plant research has increased all over the world and a large number of evidences have been collected to show the immense potential of medicinal plants used in traditional systems [1]. The olive tree (Olea europaea) has been cultivated in the Mediterranean for more than a thousand years. The positive effects on health of its fruits and oil are well known. Not only the olive oil, but also the leaves have been used for medical purposes [2,3].

Olive leaves contain different groups of constituents, such as iridoids, polyphenols, flavones and carbohydrates. Recent studies suggest that olive leaf is a significant source of bioactive phenolic compounds comparable to olive oil and fruits. There is report indicate that olive leaf contains significant amounts of oleuropein and phenolics, important factors for antioxidant capacity, which can be substantially modified by different extraction methods [4]. There is report both the individual and combined phenolics exhibited good radical scavenging abilities [5], and the relative abilities of the flavonoids from olive leaf to scavenge the $\mathrm{ABTS}^{+}$radical cation are influenced by

${ }^{*}$ Corresponding author. the presence of functional groups in their structure [6]. Besides the antioxidant activity, OLE also showed the use for anti-microbiology. Very few reports describe the activity for tyrosinase inhibitory activity, and there is also little report about the separation of OLE by chromagraphy.

The first step of present paper was to examine the antioxidant activity of OLE using the method of DPPH, superoxide anion scavenging, reducing power system. The anti-tyrosinase effect of OLE was also examined.

\section{Materials and Methods}

\subsection{Extracts from Olea europaea Leaf}

The Olea europaea olive leaf was harvested from 2011.7 to 2012.6, dried at room temperature, then grinded into powder. For extraction, two solvents (methanol and water) were used to fractionate the soluble compounds from the $O$. europaea L. leaves. The fresh leaf powder $(50 \mathrm{~g}$ per month) was mixed with water $(1: 20, \mathrm{w} / \mathrm{v})$ at $50^{\circ} \mathrm{C}$ for 3 days and the extraction was repeated three times. Using solvent methanol, the extraction was carried out at room temperature for 3 days and repeated three times, the solvents from the combined extracts were evaporated by vacuum rotary evaporator. After filtration, $1 \mathrm{~g}$ of extracts 
obtained were then transferred to vials and kept in the dark at $-20^{\circ} \mathrm{C}$ prior to use. The rest part of extracts was combined and dissolved in water, filtered through Whatman filter paper, concentrated with a vacuum evaporator and the water-soluble part was stored for next chromatography use.

\subsection{The Fraction of Chromatography}

$10 \mathrm{~g}$ Water-soluble fraction was absorbed by D101 column, eluted with water and methanol respectively, named $\mathrm{C} 1$ and $\mathrm{C} 2$ fraction. The methanol part $\mathrm{C} 2$, was recovered with a vacuum evaporator, then $\mathrm{C} 2$ fraction was separated by Sephadex LH-20, gradient elution with $250 \mathrm{~mL}$ of water-methanol system $(0 \%, 5 \%, 10 \%, 20 \%$, $40 \%, 60 \%, 100 \%$ ) respectively. By TLC detection, the elution was divided into eight fractions, named C3 - C10 and stored for next use.

\subsection{Preparation of Tyrosinase Solution}

The preparation of tyrosinase was described as following: $100 \mathrm{~g}$ fresh tomato was purchased from local market. After decorticated and chipped, the tomato was soaked in $200 \mathrm{~mL}$ phosphate buffer solution (0.2 M, pH 7.2), grinded into power and filtered by paper, the solution was centrifuged at $4000 \mathrm{~g} \times 5 \mathrm{~min}$. The supernatant was suction and stored at $-4^{\circ} \mathrm{C}$ for next use.

\subsection{Tyrosinase Activity Assay}

The determination of tyrosinase was performed used LDOPA as substrate according to the method described before [7] with slight modification. tyrosinase were determined by spectrophotometrically measuring the rate of dopachrome formation at $475 \mathrm{~nm}\left(\varepsilon=3700 \mathrm{M}^{-1} \cdot \mathrm{cm}^{-1}\right)$ by using a UV-1800 spectrophotometer. One unit of enzymatic activity was defined as the amount of enzyme transforming $1 \mu \mathrm{mol}$ of L-tyrosine or L-DOPA/min. First, $0.8 \mathrm{~mL}$ of a $2.5 \mathrm{mM}$ L-DOPA was mixed with $2.4 \mathrm{~mL}$ of $0.067 \mathrm{M}$ phosphate buffer solution (PBS, $\mathrm{pH}$ 6.6) and incubated at $37^{\circ} \mathrm{C}$ for $10 \mathrm{~min}$. Then $0.8 \mathrm{~mL}$ tyrosinase solution was added to the mixture. This solution was immediately monitored for the formation of dopachrome by measuring the linear increase in optical density at 475 $\mathrm{nm}$ for $5 \mathrm{~min}$. Triplicate measurements were recorded. The activity of L-tyrosinase activity was calculated by formula:

Tyrosinase activity $=\mathrm{k} /\left(10^{-6} \varepsilon \times \mathrm{V} \times 2.5 \times 0.1\right)$, in which $\mathrm{k}$ is slope of curve, $\varepsilon=3700(\mathrm{~mol} / \mathrm{L})^{-1}, \mathrm{~V}$ is the test volume of enzyme (here is $0.8 \mathrm{~mL}$ ).

\subsection{Determination of Tyrosinase Inhibition}

The determination of tyrosinase was performed usin LDOPA as substrate according to the method described before [7-10] with slight modification. First, $0.8 \mathrm{~mL}$ of a $2.5 \mathrm{mM}$ L-DOPA was mixed with $2.4 \mathrm{~mL}$ of $0.067 \mathrm{M}$ PBS (pH 6.6) and incubated at $37^{\circ} \mathrm{C}$ for $10 \mathrm{~min}$. Then, $0.8 \mathrm{~mL}$ of $2 \mathrm{mg} / \mathrm{mL}$ samples and $0.8 \mathrm{~mL}$ tyrosinase solution were added in this order to the mixture. This solution was immediately monitored for the formation of dopachrome by measuring the linear increase in optical density at $475 \mathrm{~nm}$ for $5 \mathrm{~min}$. Triplicate measurements were recorded. The inhibition of tyrosinase activity was calculated with the following formula:

$$
\operatorname{Inhibiton}(\%)=\frac{(\mathrm{C}-\mathrm{D})-(\mathrm{A}-\mathrm{B})}{\mathrm{C}-\mathrm{D}}
$$

where A was with sample and L-DOPA, B was with sample without L-DOPA, C was with substrate without sample, D was without substrate and samples.

\subsection{Determination of Kinetic Parameters}

To study in depth tyrosinase inhibition by OLE, we studied OLE effect on tyrosinase inhibition type, and the kinetic parameters $\left(\mathrm{K}_{\mathrm{I}}\right)$.

For determination of inhibition type, various concentrations of L-DOPA $(0.0625-10 \mathrm{mM})$ as the substrate were used. Inhibitory kinetics of samples was analyzed by Lineweaver-Burk plots. The kinetic data were plotted as 1 /activity $(1 / \mathrm{V})$ versus $1 /$ substrate concentration $(1 / \mathrm{S})$, according to the method of Lineweaver-Burk.

\subsection{Scavenging Activity of DPPH Radical}

The scavenging activity of the extract on 1,1-diphenyl2-picrylhydrazyl (DPPH), was determined according to the method of Tevfik Ozen [11] with slight modification. $0.1 \mathrm{~mL}$ of samples $(1 \mathrm{mg} / \mathrm{mL})$ or standard antioxidants solution (vitamin $\mathrm{C}, 100-6.25 \mu \mathrm{g} / \mathrm{mL}$ ) was added to a methanolic solution $\left(0.9 \mathrm{~mL}, 1.5 \times 10^{-4} \mathrm{M}\right)$ of $\mathrm{DPPH}$ radical. The mixture was shaken vigorously and kept in the dark at room temperature for 30 mins, the absorbance of the resulting solution was then measured spectrophotometrically at $517 \mathrm{~nm}$. The reduction in the absorbance of the DPPH solution indicated the free radical scavenging activities of those antioxidants. The DPPH radicalscavenging activity was calculated according to the following formula:

Scavenging rate $\left.\mathrm{E}(\%)=(1-\mathrm{A}) / \mathrm{A}_{0}\right) \times 100$

where $\mathrm{A}_{0}$ is the absorbance of the control reaction (containing all reagents except the tested compound), and A is the absorbance of the tested compound.

\subsection{Scavenging Activity of Superoxide Radical}

Superoxide radicals were generated by pyrogallic acid method with some modification [12-14]. The reaction mixture contained $2 \mathrm{~mL}$ sample $(0.0-1 \mathrm{mg} / \mathrm{mL})$ dis- 
solved in $2.25 \mathrm{~mL}$ Tris- $\mathrm{HCl}$ buffer (0.05 M, pH 8.0). After incubated at $25^{\circ} \mathrm{C}$ for 10 mins, the reaction was initiated by adding $0.075 \mathrm{~mL}$ of pyrogallol solution (10 $\mathrm{mM}$ ) for 4 mins, finally $0.02 \mathrm{~mL}$ of thick hydrochloric acid was added for termination the reaction. The optical density (OD) of the resulting solution was measured in triplicate at $420 \mathrm{~nm}$ using a spectrophotometer. Ascorbic acid was used as positive control. In blank, sample solution was substituted with Tris-HCl buffer.

The inhibition percentage of superoxide anion generation was calculated using the following formula equation:

$$
\text { Scavenging rate }=\frac{1-\mathrm{A}}{\mathrm{A}_{0}} \times 100 \%
$$

where $A$ was the absorbance of the test sample, and $A_{0}$ was absorbance of the blank. Vc was set as positive control.

\subsection{Determination of Reducing Power}

The reducing power of extracts was determined according to the Method described before $[11,13,15,16]$ with slight modification. A $1 \mathrm{~mL}$ of extract sample or standard antioxidant (ascorbic acid) was mixed with $2.5 \mathrm{~mL}$ of 0.2 $\mathrm{M}$ phosphate buffer saline $(\mathrm{pH} 6.6)$ and $2.5 \mathrm{~mL}$ of $1 \%$ $(\mathrm{w} / \mathrm{v})$ potassium ferricyanide $\left[\mathrm{K}_{3} \mathrm{Fe}(\mathrm{CN})_{6}\right]$. After the mixture was incubated at $50^{\circ} \mathrm{C}$ for $20 \mathrm{~min}, 2.5 \mathrm{~mL}$ of $10 \%(\mathrm{w} / \mathrm{v})$ trichloroacetic acid was added, and the mixture was centrifuged at $1400 \times \mathrm{g}$ for $10 \mathrm{~min}$. The upper layer of $2.5 \mathrm{~mL}$ solution was mixed with $2.5 \mathrm{~mL}$ deionized water and $0.5 \mathrm{~mL}$ of $0.1 \%(\mathrm{w} / \mathrm{v}) \mathrm{FeCl}_{3}$ for $10 \mathrm{~min}$, and then the absorbance was measured at $700 \mathrm{~nm}$. Higher absorbance of the reaction mixture indicated greater reductive potential.

\section{Results and Discussion}

\subsection{Preparations of Samples}

Samples were prepared as Figure 1. In brief, OLE was collected among 12 month and treated by chromatogramphy, finally OLE was divided into 10 fractions by its polarity.

\subsection{Antioxidant Activity of Crude Extract from 12 Months}

As shown in Figure 2, there is little difference in the extracing solvent. Reducing power and DPPH scavenging showed more active than inhibition of Superoxide anion radical.

Tyrosinase inhibitory activity was listed as Figure 3. Among 12 months, the leaf collected from autumn showed the highest acitivity, it give us a tip that autumn maybe is the better time to collect the samples.

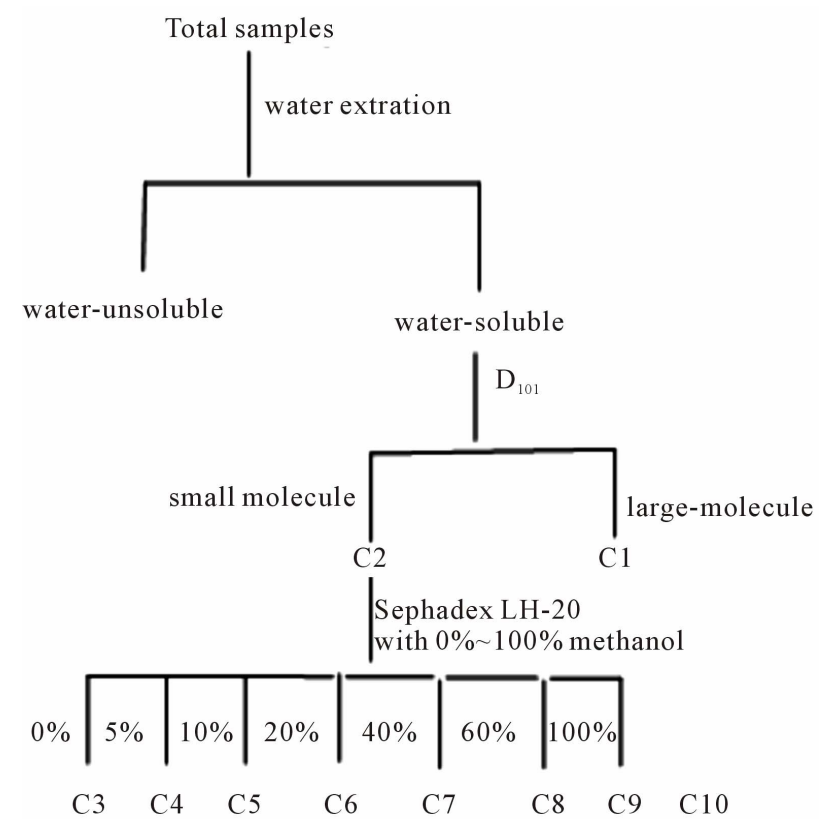

Figure 1. Flow diagram for the preparation of OLE.

\subsection{Bioactivity of 10 Chromagraphy Fraction}

\subsubsection{Antioxidant Activity of $\mathbf{1 0}$ Fractions}

The antioxidant activity and anti-tyrosinase inhibitory effect of 10 fractions were listed as Figure 4. From Figure 4, it can be seen that $\mathrm{C} 1$ fraction, major component was polysaccharide and plant protein, showed high activity in anti-tyrosinase and antioxidant activity and it prove the value of further research value. Water-soluble part was passed through Sephadex LH-20 and divided into 8 fractions by TLC detection. It can be inferred that the effect of chromatography was attained, for the activity of C3-C10 was different, and the highest among the 8 fractions was $\mathrm{C} 10$, which showed the component of high activity was low polarity.

\subsection{2. $\mathrm{IC}_{50}$ of Some Samples to Tyrosinase Inhibition}

According to the results of above, we take the highest bioactivity samples to determine the IC50, that is say the water and methanol crude extracts of October, of macromolecules samples $\mathrm{C} 1$ and $\mathrm{C} 10$. October methanol crude extracts of 0.2842 . Water-soluble part of October was $0.4073 \mathrm{mg} / \mathrm{mL}$ and $\mathrm{C} 1$ was $0.339 \mathrm{mg} / \mathrm{mL}$, and $\mathrm{C} 10$ was $0.2233 \mathrm{mg} / \mathrm{mL}$.

\subsubsection{The Inhibition Type of Tyrosinase from October Water-Soluble Part}

Preparation of gradient substrate concentration (1, 0.5, $0.25,0.125,0.0625 \mathrm{mg} / \mathrm{mL})$, the enzyme reaction rate were investigated under different substrate concentration. The results showed that the intersection of Y-axis, indicating competitive inhibition. The transversality distance 


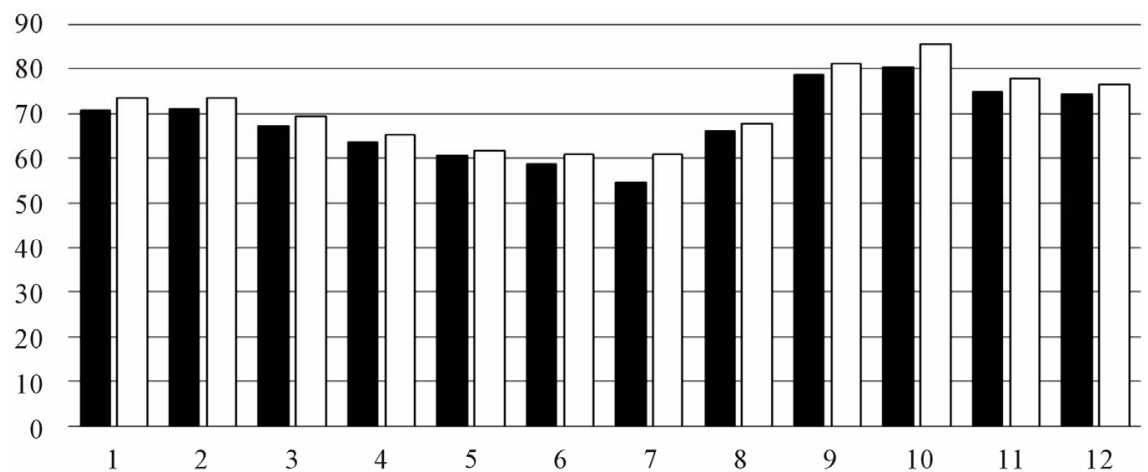

(a)

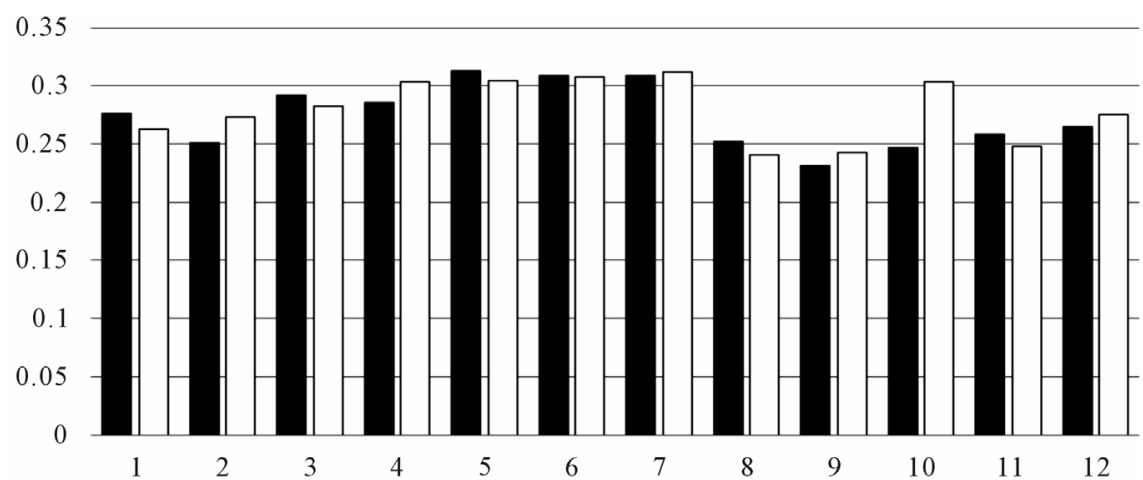

(b)

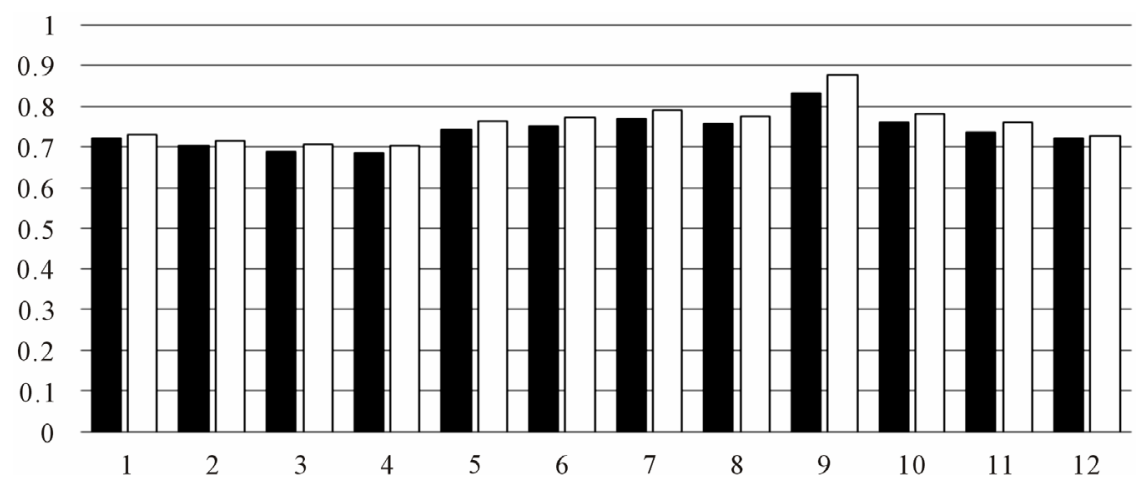

(c)

Figure 2. (a) DPPH scavenging activity by OLE extract ( $\square$ ) water-soluble part ( $\square$ ) methanolic-soluble; (b) Inhibition of superoxide anion radical ( $\square$ ) water-soluble part $(\square)$ methanolic-soluble; (c) Reducing power ( $\square$ ) water-soluble part ( $\square$ ) methanolic-soluble.

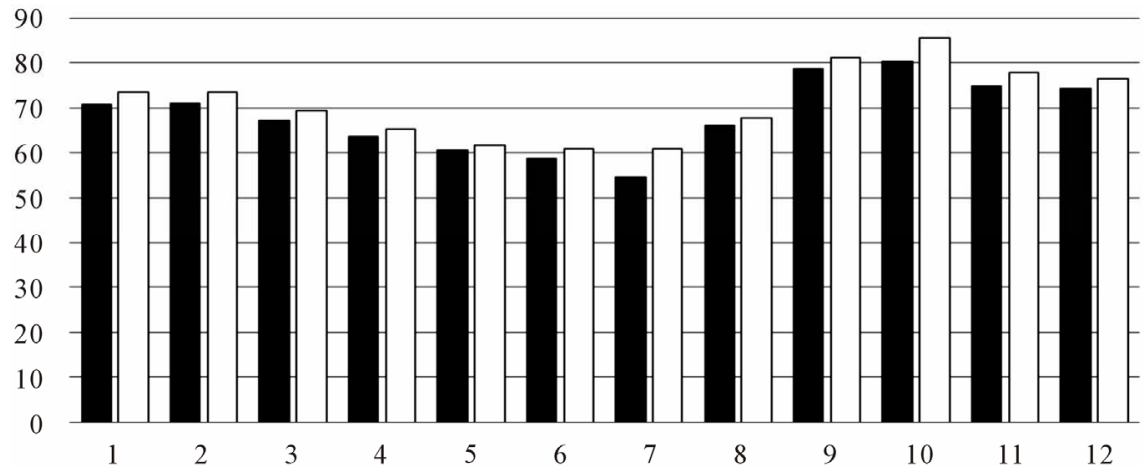

Figure 3. Anti-tyrosinase activity of OLE. 


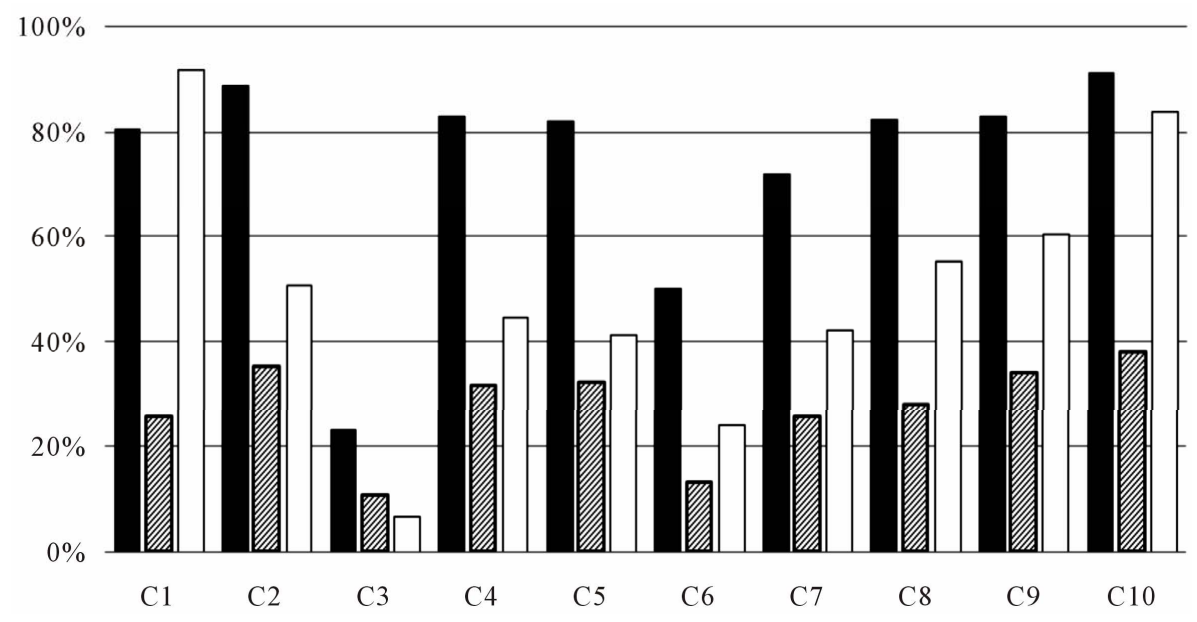

(a)

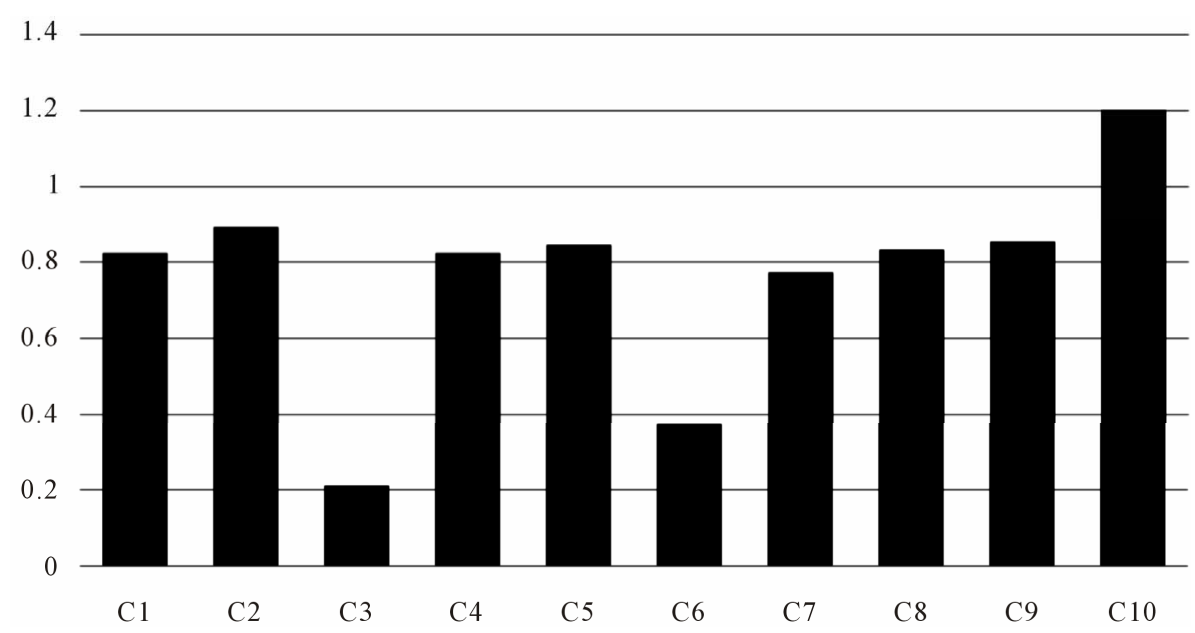

(b)

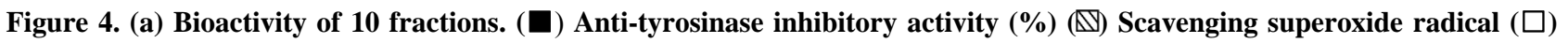
DPPH; (b) Determination of reducing power ( $\square$ ) Reducing power of 10 fractions.

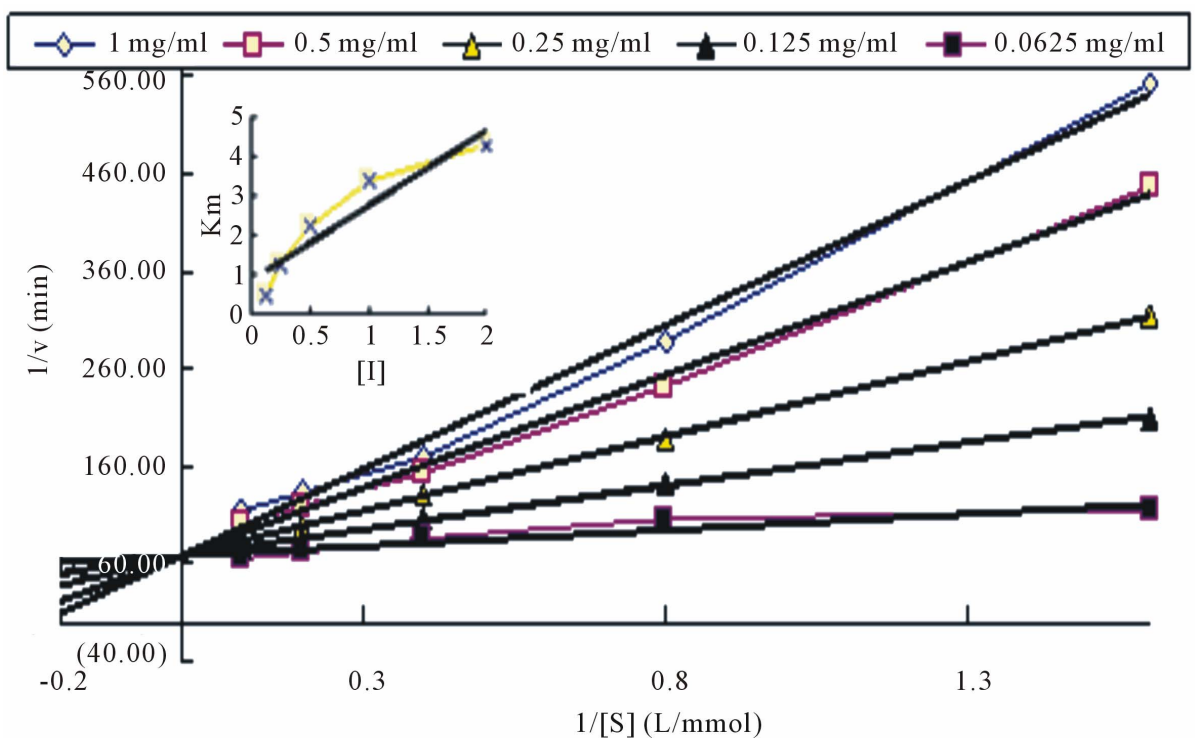

Figure 5. The plot of Lineweaver-Burk of water-soluble part. 
from the straight line can be obtained inhibition constant $\mathrm{KI}=0.226 \mathrm{mg} / \mathrm{mL}$. Data was shown as Figure 5 .

\section{Discussion}

From above, the conclusion can be drawn as followings:

On the method of extraction, the effect showed little difference on water or methanol, which indicates the major bioactivity component was water-soluble, larger polarity was better for extraction. the result was the same with Faten Brahmi's found [17]. They found the antioxidant activity of olive leaf extracts harvested at February and October, using solvents of increasing polarity (hexane, chloroform, ethyl acetate and methanol) was evaluated using DPPH and $\mathrm{ABTS}^{+}$radical-scavenging assays. The extracts were found to have different levels of antioxidant properties in the test solvent used. Higher in methanol extract than hexane, chloroform and ethyl acetate fraction. DPPH radical scavenging capacity was measured and the methanol extract showed $60 \%$ radical scavenging activity. No significant differences in antioxidant activities were found among hexane, chloroform, ethyl acetate and methanol extracts, indicating that extracts with different solvents displayed a similarly strong antioxidant activity.

The fraction of $\mathrm{C} 1$, composed of polysaccharide and plant protein, shows high antioxidant and anti-tyrosinase, which indicates further and deeper research values.

Many evidence showed OLE extract has strong antioxidant activity $[5,18,19]$.

OLE has high anti-tyrosinase activity with inhibition rate $90 \%$, and the inhibition type was competitive inhibition. this was different from Isao Kubo's conclusion. Isao Kubo [10] found a series of $\alpha, \beta$-unsaturated aldehydes, which was found to inhibit the oxidation of L-3,4-dihydroxyphenylalanine (L-DOPA) catalyzed by mushroom tyrosinase, and the inhibition kinetics analyzed by a Lineweaver-Burk plot found that they are noncompetitive inhibitors.

Olea leaf extract has been used for long time in many fields. Many evidence indicates that OLE might be a valuable bioactive source, and would seem to be applicable in both the health and medical food. These natural compounds may also prove to have therapeutic potential, as free radicals are believed to be involved in the pathogenic cascade of events in many diseases.

\section{Acknowledgements}

This study was financially supported by the Ministry of Education of China (Grant No. 20093515120005, 20113515110007), the Provincial Natural Science Foundation of Fujian (Grant No. 2012J01088, 2009N0016), the Ministry of Science and Technology of the China (Grant No. 2011AA10A203) and Fundamental Research Funds for the Central Universities (Grant No. 11J0070).

\section{REFERENCES}

[1] X. Wang, X. L. Ye, R. Liu, H. L. Chen, H. Bai and X. Liang, "Antioxidant Activities of Oleanolic Acid in Vitro: Possible Role of nrf2 and Map Kinases," Chemico-Biological Interactions, Vol. 18, 2010, pp. 328-337. doi:10.1016/j.cbi.2010.01.034

[2] R. W. Owen, A. Glacosa, W. E. Hull, R. Haubner, B. Spiegelhalder and H. Bartsch, "The Antioxidant/Anticancer Potential of Phenolic Compounds Isolated from Olive Oil," European Journal of Cancer, Vol. 36, 2000, pp. 1235-1247. doi:10.1016/S0959-8049(00)00103-9

[3] G. Boskou, F. N. Salta, S. Chrysostomou, A. Mylona, A. Chiou and N. K. Andrikopoulos, "Antioxidant Capacity and Phenolic Profile of Table Olives from the Greek Market," Food Chemistry, Vol. 94, 2006, pp. 558-564. doi:10.1016/j.foodchem.2004.12.005

[4] O. H. Lee, B. Y. Lee, J. Lee, H. B. Lee, J. Y. Son, C. S. Park, K. Shetty and Y. C. Kim, "Assessment of Phenolics-Enriched Extract and Fractions of Olive Leaves and Their Antioxidant Activities," Bioresource Technology, Vol. 100, 2009, pp. 6107-6113. doi:10.1016/j.biortech.2009.06.059

[5] O. H. Lee and B. Y. Lee. "Antioxidant and Antimicrobial Activities of Individual and Combined Phenolics in Olea europaea Leaf Extract," Bioresource Technology, Vol. 101, No. 10, 2010, pp. 3751-3754. doi:10.1016/j.biortech.2009.12.052

[6] O. Benavente-Garc, J. Castillo, J. Lorente, A. Ortuno and J. A. DelRio, "Antioxidant Activity of Phenolics Extracted from Olea europaea Leaves," Food Chemistry, Vol. 68, 2000, pp. 457-462. doi:10.1016/S0308-8146(99)00221-6

[7] M. Jime'nez, S. Chazarra, J. Escribano, J. Cabanes and F. Garciia-Carmona, "Competitive Inhibition of Mushroom Tyrosinase by 4-Substituted Benzaldehydes," Journal of Agricultural and Food Chemistry, Vol. 49, 2001, pp. 4060-4063. doi:10.1021/jf010194h

[8] C. Hsu, C. Chang, H. Lu and Y. Chung, "Inhibitory Effects of the Water Extracts of Lavendula sp. on Mushroom Tyrosinase Activity," Food Chemistry, Vol. 105, No. 3, 2007, PP. 1099-1105. doi:10.1016/j.foodchem.2007.02.008

[9] B. S. Wang, L. W. Chang, H. C. Wu, S. L. Huang, H. L. $\mathrm{Chu}$ and M. H. Huang, "Antioxidant and Antityrosinase Activity of Aqueous Extracts of Green Asparagus," Food Chemistry, Vol. 127, No. 1, 2011, pp. 141-146. doi:10.1016/j.foodchem.2010.12.102

[10] K. Isao and K. H. I. kuyo, "Tyrosinase Inhibitory Activity of the Olive Oil Favor Compounds," Journal of Agricultural and Food Chemistry, Vol. 47, 1999, pp. 4574-4578. doi:10.1021/jf990165v

[11] T. Ozen, I. Demirtas and H. Aksit, "Determination of Antioxidant Activities of Various Extracts and Essential Oil Compositions of Thymus praecox Subsp. Skorpilii var. Skorpilii," Food Chemistry, Vol. 124, No. 1, 2011, pp. 
58-64. doi:10.1016/i.foodchem.2010.05.103

[12] X. N. Liu, B. Zhou, R. S. Lin, L. Jia, P. Deng and K. Fan, "Extraction and Antioxidant Activities of Intracellular Polysaccharide from Pleurotus sp. Mycelium," International Journal of Biology Macromology, Vol. 47, No. 2, 2010, pp. 116-119. doi:10.1016/j.ijbiomac.2010.05.012

[13] M. Pan, T. S. Jiang and J. L. Pan, "Antioxidant Activities of Rapeseed Protein Hydrolysates," Food and Bioprocess Technology, Vol. 4, No. 7, 2009, pp. 1144-1152. doi:10.1007/s11947-009-0206-y

[14] B. Jiang, H. Y. Zhang, C. J. Liu, Y. Y. Wang and S. D. Fan, "Extraction of Water-Soluble Polysaccharide and the Antioxidant Activity from Ginkgo Biloba Leaves," $\mathrm{Me}$ dicinal Chemistry Research, Vol. 19, No. 3, 2009, pp. 262-270. doi:10.1007/s00044-009-9189-5

[15] D. W. Zhu, L. S. Wang, Y. Zhou, D. M. Li, L. M. Sun, J. F. Yang, H. T. Wu, H. Q. Zhou and M. Tada, "Antioxidant Activity of Sulphated Polysaccharide Conjugates from Abalone (Haliotis discus Hannaiino)," European Food Research and Technology, Vol. 227, No. 6, 2008, pp. 1663-1668. doi:10.1007/s00217-008-0890-2
[16] G. W. Zhang, L. He and M. M. Hu, "Optimized Ultrasonic-Assisted Extraction of Flavonoids from Prunella vulgaris and Evaluation of Antioxidant Activities in Vitro," Innovation of Food Science Emergency, Vol. 12, No. 1, 2011, pp. 18-25.

[17] B. Faten, M. Beligh, D. Samia, D. Madiha and H. Mohamed, "The Efficacy of Phenolics Compounds with Different Polarities as Atioxidants from Olive Leaves Depending on Seasonal Variations," Industrial Crops and Products, Vol. 38, 2012, pp. 146-152. doi:10.1016/j.indcrop.2012.01.023

[18] J. Blumberg, "Use of Biomarkers of Oxidative Sress in Research Studies" American Society for Nutritional Sciences, Vol. 134, 2004, pp. 3188s-3189s.

[19] J. E. Hayes, P. Allen, N. Brunton, M. N. O'Grady and J. P. Kerry, "Phenolic Composition and in Vitro Antioxidant Capacity of Four Commercial Phytochemical Products: Olive Leaf Extract (Olea europaea), Lutein, Sesamol and Ellagic Acid," Food Chemistry, Vol. 126, No, 3, 2011, pp. 948-955. doi:10.1016/j.foodchem.2010.11.092 